JOURNAL OF SYNCHROTRON RADIATION

Received 22 June 2020

Accepted 14 December 2020

Edited by V. Favre-Nicolin, ESRF and Université Grenoble, France

Keywords: microfluidics; X-ray fluorescence microprobe; metal geochemistry.

Supporting information: this article has supporting information at journals.iucr.org/s

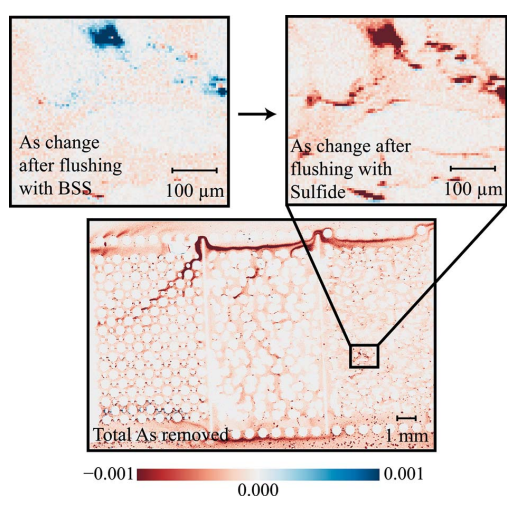

C 2021 International Union of Crystallography

\section{Development of a novel microfluidic device to study metal geochemistry in situ using X-ray fluorescence microprobe spectroscopy}

\author{
Michael A. Chen ${ }^{a, b}$ and Benjamin D. Kocar ${ }^{c, a *}$ \\ ${ }^{a}$ Civil and Environmental Engineering, MIT, 15 Vassar Street, Cambridge, MA 02139, USA, ${ }^{\mathbf{b}}$ Earth and \\ Environmental Sciences, University of Minnesota, 385-05 John T. Tate Hall, 116 Church Street SE, \\ Minneapolis, MN 55455, USA, and 'Exponent, 1055 E Colorado Boulevard, Suite 500, Pasadena, \\ CA 91106, USA. *Correspondence e-mail: bkocar@exponent.com
}

The study of in situ microscale biogeochemical processes represents a major challenge in the environmental sciences. The combination of microfluidic devices with X-ray fluorescence microprobe spectroscopy may address this need, but typical materials used in these devices attenuate the X-rays needed to analyze key elements of interest, such as Fe or As. In this work, a method is presented for fabricating an etched silicon microfluidic device that is sealed with a $30 \mu \mathrm{m}$ thin glass window that is sufficiently transparent for X-ray fluorescence microprobe spectroscopy. The capabilities of these devices for X-ray microprobe spectroscopy are demonstrated using an Fe (hydr)oxide solid that is loaded with As and then infused with sulfide, on beamline 4-BM at NSLS-II, resulting in time-variant $\mathrm{Fe}$ precipitation reactions and As sorption. Key results include in situ X-ray fluorescence time-series maps of $\mathrm{Fe}$, As and a $\mathrm{Br}$ flow tracer, as well as spot XANES at both the Fe $K$ edge and As $K$ edge. Additionally, multiple energy mapping is used to examine the spatial speciation of As over time. The results of this work clearly demonstrate the capabilities of this novel microfluidic system that can be analyzed using X-ray fluorescence microprobe spectroscopy and can be made to study a wide range of complex microscale geochemical systems.

\section{Introduction}

Processes and heterogeneities at scales as small as individual pores have been observed to impact the geochemical transport of metals at larger scales. For example, studies of U contamination at Hanford, Washington, USA, demonstrated that uranium accumulated in microfractures of natural soil materials, potentially acting as a continuing source of uranium to the groundwater beyond predicted flushing times (McKinley et al., 2006). In contrast, at the U-contaminated site near Rifle, Colorado, USA, naturally reducing zones, which form under the confluence of high water saturation, limited physical transport and high organic carbon, slowly leach U as oxygen oxidatively dissolves $\mathrm{U}^{\mathrm{IV}}$ solids (Janot et al., 2016). Laboratory experiments have demonstrated that anoxic zones can develop in soil aggregates, whose existence in metalcontaminated soils could create micro-zones of $\mathrm{Cr}$ retention or As release in a contaminated soil (Masue-Slowey et al., 2011). These studies highlight that understanding geochemical processes at bulk scales necessitates experimental study of how those processes operate at pore scales. Many of the highly sensitive analytical chemistry methods, however, such as 
inductively coupled plasma mass spectrometry or optical emission spectrometry, cannot easily resolve spatial variations in chemistry, while spatially resolved methods such as X-ray photoelectron spectroscopy require specialized preparation of samples via sample polishing and other cleaning that is disruptive to natural geochemistry and soil structure.

$\mathrm{X}$-ray fluorescence (XRF) microprobes have played a central role in the study of these microscale processes that drive the cycling of elements and contaminants in the environment. XRF microprobes can be used to collect information on the distribution of elements via XRF mapping, but can also be used to differentiate between certain oxidation states or ligands complexing a given element through collection of $\mathrm{X}$-ray absorption near-edge structure (XANES) spectra while preserving sample structure and geochemistry (Root et al., 2013; Prietzel et al., 2007; Foster \& Kim, 2014). For example, soil aggregates and rock cores have been analyzed with an XRF microprobe to track and map As species distributions as a function of redox conditions (Masue-Slowey et al., 2011; Nicholas et al., 2017). Multi-energy mapping, a hybrid method combining XRF mapping and XANES, also allows for mapping of different species at microscales that are relevant to these microscale soil processes (Root et al., 2013; Mayhew et al., 2011). This has been used to study $\mathrm{Ni}$ and Co incorporation into mackinwite, as well as the spatial distribution of $\mathrm{Mn}$ species in deep-earth samples linked to the rise of photosynthetic bacteria (Swanner et al., 2019; Johnson et al., 2013). A major challenge in quantifying environmental processes, particularly those in soils and sediments where groundwater flow coupled with microscale geochemistry dominates contaminant and nutrient fate, is observing these processes at work in situ. While XRF microprobe spectroscopy provides an analytical technique to examine environmental geochemistry at the microscale, there is a need for an experimental system that can be tailored to study these processes specifically under controlled conditions.

Microfluidic devices are a tool that could fill this need. Typically, these consist of a 2D pattern of channels that have been etched into a material or cast from a mold, sealed with a transparent window material and then filled with solutions of interest. This allows for tailoring of both flow and geochemical conditions that can match what is found environmentally, but in an experimental system that can be observed directly without further modification. These devices are commonly used to study microbiological processes or multiphase flow and can be designed to replicate many different soil structures and mineralogies (Oostrom et al., 2016; Kim \& Fogler, 2000; Wang et al., 2018; Yawata et al., 2016). Indeed, etched silicon micromodels have already been used to study geochemical processes, including precipitation and dissolution of calcium carbonate, the impact of natural pore structures on hematite reduction kinetics, and uranyl phosphate precipitation (Zhang et al., 2013; Yoon et al., 2012; Fanizza et al., 2013; Lee et al., 2016; Jaho et al., 2016; Song et al., 2014). Others have used these devices to quantify how spatial limitations impact microbial reduction of metals (Michelson et al., 2017).
Microfluidic devices are typically sealed with a $500 \mu \mathrm{m}$ glass cover slip through anodic bonding or plasma bonding of poly(dimethylsiloxane) (PDMS) (Kim et al., 2011; Cui, 2008). One study of $\mathrm{Fe}$ and $\mathrm{U}$ cycling with a metal-reducing bacterium in a micromodel used XRF microprobe spectroscopy to study $U$ distributions through $U L$-edge spectroscopy directly and then through $\mathrm{Fe} K$-edge spectroscopy by sectioning the device, but glass attenuation has, for the most part, confounded efforts to study microscale processes in situ using an XRF microprobe (Pearce et al., 2012). Innovations in glass fabrication techniques, however, have allowed for the fabrication of glasses as thin as $25 \mu \mathrm{m}$, which would drastically reduce $\mathrm{X}$-ray attenuation and lead to a device that could overcome this technical challenge.

Arsenic geochemistry is well suited to proving the capabilities of such a device and As is also a high-priority soil/ groundwater contaminant in a wide range of settings. Exposure to As-containing waters or foods results in significantly elevated cancer risks, along with internal organ damage (Huhmann et al., 2017). In Southeast Asia, natural mineral formations release arsenic when groundwater is hydrologically pumped, resulting in contamination of drinking water sources (Berg et al., 2001; Neumann et al., 2010). A variety of geochemical processes control arsenic distribution and fate. Reduced As, arsenite, sorbs significantly to $\mathrm{Fe}$ and $\mathrm{Mn}$ (hydr)oxide phases and can form more recalcitrant As-S phases such as orpiment or realgar. In contrast, oxidized As, arsenate, sorbs less strongly to these mineral phases, and thus oxidation of arsenite can cause release of arsenic into groundwater (Dixit \& Hering, 2003; Farquhar et al., 2002; Burton et al., 2014). Injection of sulfide has been considered as a means of attenuating As concentrations by formation of orpiment and other As-S solids (Wolthers et al., 2005). However, this could cause transformation of highly sorbing Fe (hydr)oxide minerals into less-sorptive reduced iron minerals, or in some cases Fe sulfides, possibly resulting in the release of As rather than its retention. The multifaceted interactions between Fe minerals, As phases/minerals and sulfide make for an ideal system to test an XRF-capable microfluidic device, as a variety of XRF techniques will be required to study changes in As and Fe speciation, as well as shifts in distribution as a result of sulfide injection.

In this work we develop and study an etched silicon microfluidic device containing As, Fe and $\mathrm{S}$ using in situ XRF microprobe spectroscopic techniques. The device features a $30 \mu \mathrm{m}$ thick glass window which maintains geochemical similarity to natural soils, while allowing for XRF spectroscopy using energies as low as $7 \mathrm{keV}$. Two different device designs were used to illustrate the range of structure and flow conditions that could be created in these devices, while the Fe-As-S geochemical system is meant to be representative of a complex geochemical system that could be found in natural soil systems. Reactions that were considered included tracking the transformation of different Fe mineral phases, As sorption and precipitation with sulfide, and coupled redox reactions between the three primary components. 


\section{Materials and methods}

\subsection{Fabrication, sealing and re-use of micromodels}

Microfluidic devices were etched into silicon using established microfabrication techniques at the Harvard Center for Nanoscale Systems (Chomsurin \& Werth, 2003; Pearce et al., 2012; Michelson et al., 2017). Briefly, soft photolithography is used to pattern a positive photoresist on a silicon wafer using a mask printed on a laminate (see the supporting information for details of mask preparation). Typically, multiple devices are patterned onto a single wafer for efficiency of fabrication. The silicon wafer is then etched to $30 \mu \mathrm{m}$ depth using an inductively coupled plasma deep reactive ion etch (ICPDRIE) apparatus. After this, the devices are separated by breaking the wafer along the lines between individual devices, ports are drilled with an ultrasonic drill (LUD200 LLC, Kingsley North) and then excess residues from etching are cleaned with plasma ashing ( $200 \mathrm{~W}, 10 \mathrm{~min})$. Cleaned devices were then fired in a muffle furnace at $1273 \mathrm{~K}$ for at least $2 \mathrm{~h}$ to form a thin coating of thermal $\mathrm{SiO}_{2}$ that mimics the wettability and geochemistry of natural earth materials, such as quartz. The smallest separation between features that was achieved was $10 \mu \mathrm{m}$, but it should theoretically be possible to achieve better spatial resolution through the use of chrome-plated glass masks and further optimization of the lithography parameters (Marty et al., 2005).

Etched devices were sealed with the thin glass using a transfer adhesion process. A freshly mixed two-part epoxy adhesive (Devcon 14310) is spread on a flat, clean surface (e.g. aluminium foil) and then a clean layer of Kapton tape is carefully rolled over the uncured epoxy. Note that the nonadhesive side of the tape is used. Excess epoxy on the tape is then repeatedly rolled off on the clean surface until a thin layer remains on the Kapton. The epoxy on the Kapton is then carefully rolled onto the silicon device, resulting in a thin layer on the top of the microfluidic device, but not in the channels. This was confirmed through visual inspection with an inverted microscope under $10 \times$ magnification. The $30 \mu \mathrm{m}$ thick glass from Schott (AF-32 Eco) was cut to an appropriate size using a glass cutter, cleaned with acetone/propan-2-ol, dried, and carefully placed on the microfluidic device immediately after epoxy application. Light pressure was applied by hand to ensure contact between the glass and epoxy, and the device examined with brightfield microscopy to confirm that epoxy had not overfilled into the channels. In cases of observed epoxy overfill into the microfluidic device or of misalignment, the device was soaked in acetone and the glass carefully removed, followed by rinsing of all surfaces with propan-2-ol, and the coating process was repeated. This could typically recover both the device and the window material if done within an hour of epoxy application. After the cure time for the epoxy had passed $(16 \mathrm{~h})$, the edges of the glass were sealed with a UV-curable glue to prevent device leakage. IDEX Health and Science nanoports (N-333) were then mounted to the drilled holes using the same two-part epoxy used to attach the glass. Epoxy was added in between the ports to create a stabilizing layer on the back of the microfluidic device.

\subsection{Methods for running micromodels}

Devices were infused with solutions either by injecting solutions into the inlet port(s) or connecting device inlets to reservoirs of solution and using syringes connected to the outlet port(s) to draw flow through the device (Fig. 1). Both means were used to introduce solutions into the devices. Gastight glass syringes (Hamilton) were preferred over plastic: the use of plastic syringes introduced air into the devices as the connections were not gas tight, and provided substantially more variation in pumping rate owing to plastic deformation.

In the case of injection, the desired solutions were preloaded into syringes using the following method. The barrel of a filled syringe closed with a two-way valve was withdrawn while closed to exsolve gases, and then bubbles tapped to the inlet and the valve opened and excess gas expelled. This process was repeated multiple times until minimal gases exsolved. In order to switch solutions, the syringes had to be swapped, which sometimes introduced air bubbles. While heating has been used by other groups to reduce gas exsolvation, it was not as effective here, since the major air sources were air trapped when re-connecting syringes (Pearce et al., 2012).

When running the devices by withdrawal, vented serum bottles containing the desired solution were connected to

(a) Injection

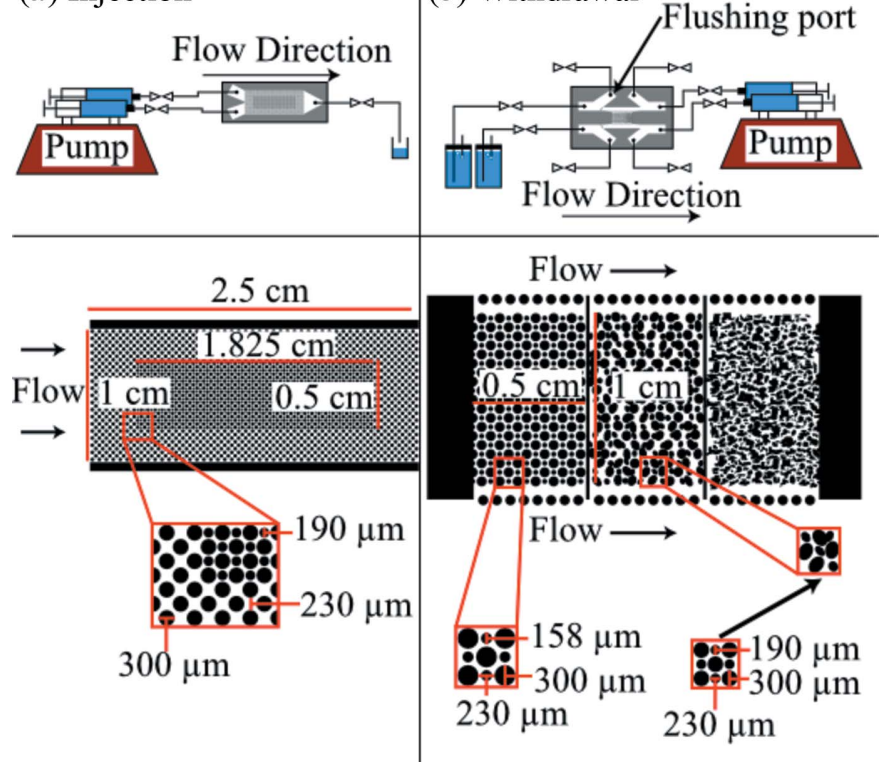

Figure 1

(Top) Schematics of running microfluidic devices by $(a)$ injection and $(b)$ withdrawal. (Bottom) Schematics of the channel designs used in this work. (Left) The diverging-flow device, featuring a tight central pore space surrounded by a looser pore space, where flow is directly infused into the pore space. (Right) Three different pore spaces with matching porosity bracketed by flow channels. Solutes enter the pore space via transverse mixing. The leftmost space is adjusted from the tight pore space in the diverging-flow device by adjusting the size of the interstitial posts. The middle space is derived from the tight pore space in the diverging-flow device by randomizing the locations and morphology of the posts. The rightmost space is derived from a CT scan of Berea sandstone and modified to match the target porosity (Boek \& Venturoli, 2010). 
injection flow lines via a needle (Fig. 1). Switching solutions was simpler in this case, as the needles prevented the introduction of additional air and trapped air could be tapped away from the needle inlet before it could be pulled into the flow lines.

In either method for running devices, low flow rates $\left(<500 \mu \mathrm{h} \mathrm{h}^{-1}\right)$ were used, as excess positive pressure during injection could break the coverslip and excess negative pressure during withdrawal could lead to gas exsolvation. In all cases, valves were connected in line on all lines running to and from the devices. When making alterations to the flow configuration while running the devices (e.g. swapping solutions, purging air in lines), these switches were closed to isolate pressure changes caused by making and breaking fluidic connections.

The major difficulties in running microfluidic devices were displacing air during initial device filling, operating devices in a manner that prevented further introduction of bubbles, and removing air bubbles remaining in the device after filling. A variety of methods were applied here with varying degrees of success. Pre-filling with propan-2-ol displaced air well, as did pre-filling with freshly boiled de-ionized (DI) water. A risk with using propan-2-ol to pre-fill, however, is that it can weaken the epoxy bonding the glass window. When propan-2ol was used to pre-fill, it was flushed with DI water or background salt solution (see Section 2.3) within 10 min of application. Flushing with solutions that had been boiled for at least $1 \mathrm{~h}$ was also efficient at removing air bubbles, even after initial filling. Some of the device designs featured in this work had additional installed ports which were meant to be used to flush air bubbles that had appeared in the device prior to the study region. These were useful for removing air bubbles that had reached the device inlets, but also introduced additional flows that obfuscated patterns of flow.

\subsection{Experimental solutions}

All experimental solutions were made using ACS grade chemicals or better in $18 \mathrm{M} \Omega$ or higher water. Solutions sensitive to the presence of oxygen (e.g. $\mathrm{Fe}^{\mathrm{II}}, \mathrm{S}^{-\mathrm{II}}$ etc.) were prepared in an anoxic glove bag (Coy Labs) with a $2 \%$ to $3 \%$ $\mathrm{H}_{2}$, balance $\mathrm{N}_{2}$, atmosphere. Oxygen levels in the glove bag were always less than 1 p.p.m. Solutions that needed transport to beamline facilities or other locations were kept in smaller anoxic boxes which were sealed in the glove bag and opened only immediately before usage. For all experiments, a basal salts solution (BSS) with Na-PIPES [piperazine- $N, N^{\prime}$-bis(2ethanesulfonic acid)] buffer titrated to $\mathrm{pH} 7.10 \pm 0.05$ was used to represent a typical groundwater system (Kocar et al., 2006). The composition is listed in Table S1 in the supporting information. Microfluidic devices were pre-loaded with an iron (hydr)oxide phase by infusing the oxic BSS and an anoxic solution containing 1 to $10 \mathrm{mM} \mathrm{Fe}^{\mathrm{II}}$ in separate channels. These solutions mixed within the device, leading to the formation of $\mathrm{Fe}$ (hydr)oxide coatings. Higher Fe concentrations lead to faster development of the Fe (hydr)oxide coating. BSS containing an addition of $250 \mu M \mathrm{NaAsO}_{2} / 250 \mu M$
$\mathrm{Na}_{3} \mathrm{AsO}_{4} / 10 \mathrm{~m} M \mathrm{NaBr}$ or $1 \mathrm{~m} M \mathrm{Na}_{2} \mathrm{~S} / 10 \mathrm{~m} M \mathrm{NaBr}$ were used through the experiments to introduce $\mathrm{As}$ and $\mathrm{S}$. $\mathrm{NaBr}$ was included in these solutions as a flow tracer.

\subsection{Device configurations and running parameters}

Two different micromodel patterns were used in the experiments; the setups and key details of the features are given in Fig. 1. In one, a regularly repeating post structure ( $300 \mu \mathrm{m}$ posts with $70 \mu \mathrm{m}$ post separation) is present in the device. In the center, there is a tight pore space which has $190 \mu \mathrm{m}$ posts in between the large posts, which creates a tighter pore region that splits the flow. This pore space was connected to two inlet channels and one outlet channel and was infused with solutions by injection. These devices were first seeded with an Fe (hydr)oxide mineral as discussed above by mixing an anoxic $\mathrm{Fe}^{\mathrm{II}}$-containing solution and oxic BSS within the device and then replacing the $\mathrm{Fe}^{\mathrm{II}}$ solution with the mixed $\mathrm{As}^{\mathrm{III}} / \mathrm{As}^{\mathrm{V}} / \mathrm{Br}^{-\mathrm{I}}$ solution.

In the other device pattern, three different pore regions with a porosity of 0.33 are located in between two parallel channels ( $2 \mathrm{~mm}$ wide when next to the pore space) that connect two pairs of injection ports and outlet ports (Fig. 1) and are infused with solution by withdrawal from vented reservoirs.

Transport of solutes into the pore spaces from the flow channels was meant to occur primarily through dispersion, though the $\mathrm{Br}$ tracer revealed that significant transverse mixing occurred (see Section 3.1 for results). The pore region nearest the inlets has a repeating pattern of $300 \mu \mathrm{m}$ posts with $190 \mu \mathrm{m}$ posts between the larger posts separated by $20 \mu \mathrm{m}$. The middle space was derived from the central pore space of the flow-diverging device by applying a randomization of each post in Adobe Illustrator (parameters given in Table S2), which resulted in a region that matched the target porosity. The region closest to the outlet was derived from an image of a sandstone and edited to match the target porosity (Boek \& Venturoli, 2010). The porosities of these pore spaces were measured directly from the pore image using a simple Python script (Python Software Foundation, 2010) that calculated the area of the image that was void.

The purpose of this design was to study the transport and reaction of solution species in pore spaces where the dominant mode of transport was dispersion and subsequent transverse mixing. The solution sequence was the following. First, the devices were infused with $\mathrm{Fe}^{\mathrm{II}}$ and $\mathrm{BSS}$ to precipitate $\mathrm{Fe}$ (hydr)oxides. Then, BSS containing mixed $\mathrm{As}^{\mathrm{III}} / \mathrm{As}^{\mathrm{V}} / \mathrm{Br}^{-\mathrm{I}}$ was infused in one channel while straight BSS was infused in the other channel. Both channels were then flushed with BSS, before finally injecting BSS containing $1 \mathrm{~m} M \mathrm{~S}^{-\mathrm{II}} / 10 \mathrm{~m} M \mathrm{Br}^{-\mathrm{I}}$ into the same channel where the $\mathrm{As} / \mathrm{Br}$ solution had been injected. During device filling, flow rates as high as $500 \mu \mathrm{l} \mathrm{h}^{-1}$ were used for each channel, while during XRF data collection, flow rates from 5 to $50 \mu \mathrm{h} \mathrm{h}^{-1}$ were used in each channel. Solutions were flowed into the devices via the main channels until a steady-state distribution of the injected chemical was reached in the pore space, which typically took a few hours, as 
indicated by the $\mathrm{Br}$ tracer. In some cases, the flow lines leading to the microfluidic device were pre-loaded with the desired solution to reduce run times using the flushing ports on the microfluidic device. These ports were intended to provide a means of driving a solution through the flow lines without introducing it to the pore space.

\subsection{Device characterization}

The micromodels were imaged using brightfield microscopy on an inverted microscope (Olympus) using a scientific camera (AmScope). Brightfield maps of a device were taken using Micromanager (Edelstein et al., 2014), then stitched using Microsoft Image Composite Editor (Edelstein et al., 2010). Chemical characterization was performed using the XRF microprobe on beamline 4-BM at NSLS-II (Brookhaven National Laboratory, Upton, New York, USA). Both fluorescence mapping and spot X-ray absorption spectroscopy (XAS) were performed on the devices. The desired X-ray energies were generated by a three-pole wiggler, pre-focused using a toroidal mirror and vertical collimating mirror before passing through a $\langle 111\rangle \mathrm{Si}$ double-crystal monochromator. The final focusing was performed using a set of KirkpatrickBaez focusing mirrors which achieved X-ray spot sizes of $5 \mu \mathrm{m}$ to $9 \mu \mathrm{m} \times 5 \mu \mathrm{m}$. The resultant $\mathrm{X}$-ray flux was $10^{11}$ photons s $^{-1}$. $\mathrm{X}$-ray fluorescence for both mapping and XANES spectroscopy was measured using a Hitachi Vortex ME4 detector with Quantum Detectors XSpress3 electronics. The $\langle 111\rangle \mathrm{Si}$ monochromator was calibrated to $7111 \mathrm{eV}$ using an iron foil in transmission. This calibration was compared against a $\mathrm{Cr}$ foil at $6989 \mathrm{eV}$ and was stable over the week of data collection. The As ${ }^{\mathrm{V}}$ edge was calibrated to $11874 \mathrm{eV}$ using As sorbed to ferrihydrite. Owing to the possibility of radiation damage affecting the results (see supporting information), care was taken to minimize sample exposure outside of making specific measurements.

Microfluidic devices were characterized both with no flow induced and during flow. Mapping was performed at $14 \mathrm{keV}$ with dwell times that varied from $50 \mathrm{~ms}$ to $200 \mathrm{~ms}$. Spot sizes were changed depending on the scan resolution used to prevent oversampling ( $5 \mu \mathrm{m}$ to $45 \mu \mathrm{m}$ steps). Maps were collected by obtaining a full spectrum at each pixel and fitting the collected spectra to get elemental maps. Scans of the XANES region for Fe and As were taken using the following scheme: from $-100 \mathrm{eV}$ to $-10 \mathrm{eV}$ around the edge $(7111 \mathrm{eV}$ for $\mathrm{Fe}, 11867 \mathrm{eV}$ for As), steps were taken every $5 \mathrm{eV}$; from $-10 \mathrm{eV}$ to $50 \mathrm{eV}$, steps were taken every $0.25 \mathrm{eV}$; finally, from $50 \mathrm{eV}$ to $300 \mathrm{eV}$, steps were taken every $2 \mathrm{eV}$. The dwell time for each step varied from 0.5 to $2 \mathrm{~s}$ per step. Multiple XANES spectra were successively gathered for a given point to improve data quality. These spectra were then aligned and averaged using Athena (Ravel \& Newville, 2005). Multipleenergy (ME) mapping was also performed for As to examine spatial patterns of As speciation (Mayhew et al., 2011; Root et al., 2013). Maps for As were taken at 11 869, 11 872, 11875 and $11880 \mathrm{eV}$, otherwise using the same mapping parameters as described above (Root et al., 2013). Fitting of collected ME maps to produce images with speciation was performed using SMAK (Webb, 2011). The background XRF spectrum of the glass is provided in the supporting information, alongside a discussion of the interfering elements in the thin glass.

\section{Results}

\subsection{Elemental mapping}

Iron (hydr)oxide precipitates formed after injection of $\mathrm{Fe}^{\mathrm{II}}$ and PIPES-buffered BSS were first mapped using both brightfield microscopy and XRF microprobe mapping at $14 \mathrm{keV}$. Representative images taken from the diverging-flow devices are given in Fig. 2, while representative images from the parallel-flow devices are given in Fig. 3. In the brightfield images, the red-brown Fe precipitate can be very clearly seen alongside the silicon pore structure, with bands of Fe bending around the device posts. The distribution of precipitate clearly matches the Fe $K$ fluorescence maps, indicating that the observed precipitate is predominantly $\mathrm{Fe}$ in all devices that were studied. Brightfield images of the diverging-flow device show a heterogeneous distribution of Fe (hydr)oxides, which only partially penetrate into the tighter pore space in the center of the device, as confirmed by observations of $\mathrm{Fe}$

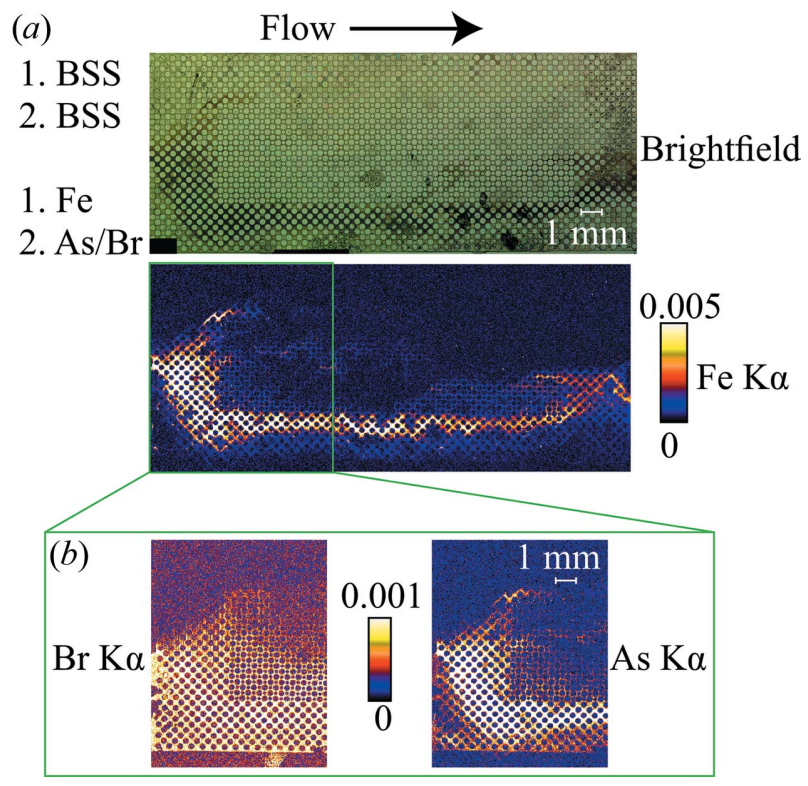

Figure 2

Stitched brightfield images and XRF fluorescence maps (45 $\mu \mathrm{m}$ step for $\mathrm{Fe}$ and $35 \mu \mathrm{m}$ for $\mathrm{As} / \mathrm{Br}$ ) for the diverging-flow device. The dark redbrown precipitate seen in the microscope images matches the $\mathrm{Fe}$ distribution shown the XRF maps. The distribution of As also matches the Fe distributions along the side of the device where the As was injected, while $\mathrm{Br}$ is not specifically associated with $\mathrm{Fe}$. The colorbar gives the element fluorescence signal normalized to $I_{0}$, with the lowest color value being set to 0 , which was below the detection threshold. The detection threshold was not rigorously determined in these experiments. Areas corresponding to the solid pores, which should have no infused chemicals, had approximately $3 \times 10^{-4}$ normalized counts for $\mathrm{Br}$ maps, $1 \times 10^{-4}$ for As maps and $1 \times 10^{-4}$ for Fe maps. These values give a rough estimate of the background fluorescence for these mapping conditions. 
(a)

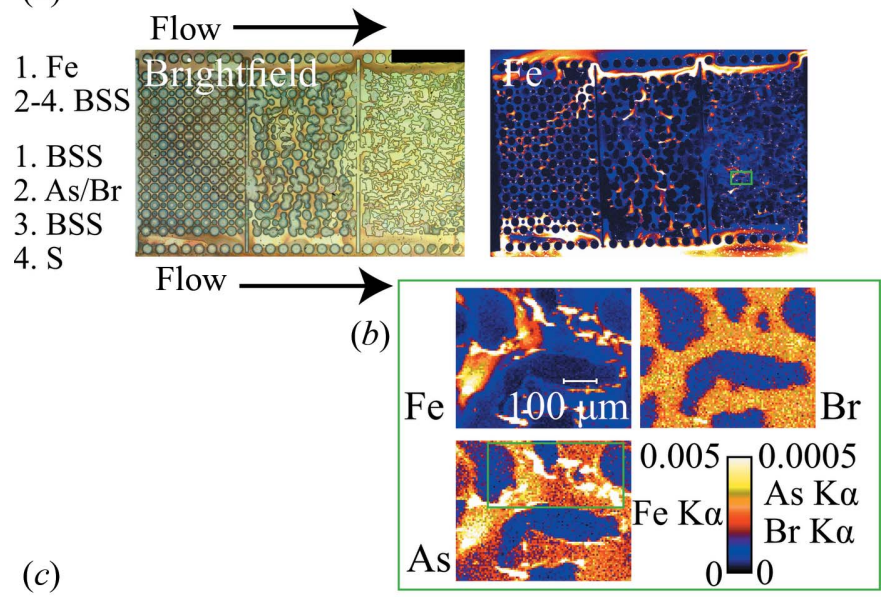

(c)

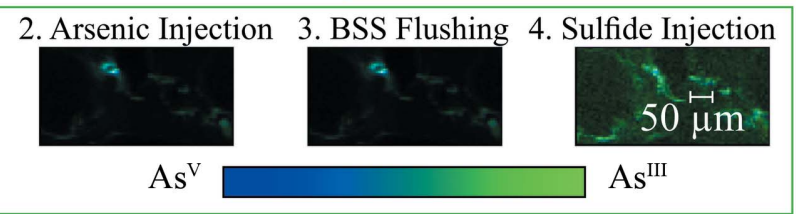

Figure 3

Assorted imaging results for a representative parallel-flow device. (a) Brightfield (left) and $\mathrm{Fe} K \alpha$ (right) maps show the extent of $\mathrm{Fe}$ precipitates in the device as a result of alternating the channels of $\mathrm{Fe}$ injection. (b) A series of $5 \mu \mathrm{m}$ resolution fluorescence maps for $\mathrm{Br} K \alpha$, Fe $K \alpha$ and As $K \alpha$ are shown for the small region outlined in green in panel $(a)$. Fluorescence results are given in counts normalized to the incident X-ray energy, $I_{0}$. $(c)$ Results from ME mapping a subregion of the mapped regions in panel $(b)$ over the major reaction stages. Arsenic speciation shifts from a mixed $\mathrm{As}^{\mathrm{V}}$ and $\mathrm{As}^{\mathrm{III}}$ to predominantly $\mathrm{As}^{\mathrm{III}}$ as $\mathrm{As}$ is flushed and then sulfide injected. The values of fluorescence in the solid pores were approximately $1 \times 10^{-4}$ for Fe maps, $5 \times 10^{-5}$ for As maps and $1 \times 10^{-4}$ for $\mathrm{Br}$ maps, which are similar to the background values in Fig. 2.

fluorescence in similar locations. The precipitates are primarily downstream of injected $\mathrm{Fe}^{\mathrm{II}}$, although some can be clearly observed on the opposite side (downstream of the injected PIPES buffer and BSS) in both brightfield and Fe fluorescence images. Chunks of $\mathrm{Fe}$ can also be clearly observed, especially in the finer maps $(20 \mu \mathrm{m}$ step size or smaller), probably corresponding to small pieces of $\mathrm{Fe}$ (hydr)oxide mineral. In the parallel-flow devices, the Fe and BSS injections were swapped throughout the precipitation process, resulting in Fe precipitates in all of the pore regions. The maps clearly demonstrate that while the Fe precipitates have broadly reached all of the pore regions, the distribution is highly heterogeneous over the device, featuring similar types of 'hot spots' as observed in the diverging-flow devices.

Bromide was used as a non-reactive tracer to track the mixing state of the different device injections after Fe was precipitated. Br distributions were determined by measuring $\mathrm{Br} K$ fluorescence with an incident $\mathrm{X}$-ray energy of $14 \mathrm{keV}$ and all $\mathrm{Br}$ is assumed to be $\mathrm{Br}^{-\mathrm{I}}$. For the diverging-flow devices, $\mathrm{Br}$ was injected with the mixed As solution. In these maps, the divergent nature of the flow, brought on by the tight central pore space, becomes apparent, with $\mathrm{Br}^{-\mathrm{I}}$ primarily remaining on the side of the device it was injected in. In contrast, $\mathrm{Br}^{-\mathrm{I}}$ tracer infused into one channel of the parallel flow path devices showed that the pore spaces are generally well mixed, with $\mathrm{Br}$ reaching all parts of the device pore region (typically after $\sim 500 \mu \mathrm{l}$ was infused). Maps of one device after each major solution infusion (i.e. As/Br in BSS, BSS flush, $\mathrm{S} / \mathrm{Br}$ in BSS) are given in the supporting information (Fig. S2). The specific solution sequence used after Fe precipitation was mixed $\mathrm{As}^{\mathrm{III}} / \mathrm{As}^{\mathrm{V}} / \mathrm{Br}$ in $\mathrm{BSS}$, flushing with BSS, finally ending with $\mathrm{S} / \mathrm{Br}$ in $\mathrm{BSS}$. In between $\mathrm{Br}$ injection steps, maps of $\mathrm{Br}$ show that all the $\mathrm{Br}$ is flushed (supporting information).

In both types of device, precipitation of Fe was followed by infusion of a mixed As solution containing $250 \mu \mathrm{MAs}{ }^{\mathrm{III}}$ and $250 \mu M \mathrm{As}^{\mathrm{V}}$ into one side of the device. In all experiments, As was primarily co-located with Fe (Figs. 2, 3 and S2). In the case of the diverging-flow device, As does not readily appear in the side opposite to its injection, matching the distribution indicated by the $\mathrm{Br}$ tracer. In the case of the parallel-flow device, As is co-located with $\mathrm{Fe}$ in all of the pore regions, which also matches the observed $\mathrm{Br}$ distribution. After filling the parallelflow devices with As solution, the channel containing As was flushed with BSS and then infused with BSS containing $1 \mathrm{mM}$ $\mathrm{S} / 10 \mathrm{~m} M \mathrm{Br}$. Maps showing the change in As concentration after each of these infusion stages (As/Br, BSS flush, S/Br) are discussed below. Broadly, flushing with BSS primarily redistributed As, while sulfide injection resulted in a loss of As across the whole device.

Difference maps used to compare normalized As fluorescence were produced by calculating the displacement of static features between time points, aligning and cropping images based on those displacements, and then subtracting the resultant cropped maps. Determination of the static features was done manually, while the alignment, cropping and subtraction were done via a simple Python script (Python Software Foundation, 2010; Virtanen et al., 2020). The displacements were calculated by manually measuring the pixel displacement between static features (i.e. silicon posts that were not affected by reaction) found after every reaction step and then applying that displacement to the coordinates embedded in the map. This resulted in maps which had aligned coordinates but did not perfectly overlap, thus they were cropped so that the compared images were the same size. Once the maps had been aligned and cropped, the relevant normalized fluorescence channels (As $K \alpha$ ) were subtracted to produce the difference image.

Changes between As filling, subsequent BSS flushing and then filling with $1 \mathrm{~m} M$ sulfide are shown in Fig. 4. Changes in As counts between As filling and BSS flushing show shifts in As distribution, and in some regions net loss of As. The infusion of BSS should have a minimal effect, or should remove some As owing to mass action and removal of As that was in solution. After sulfide introduction, regions show losses of As from mapped areas, with none of the previously observed redistribution. A difference map of As change from initial injection of As to injection of $S$ for the whole device shows that a net loss of As occurs over the whole device in most regions. Overall, sulfide drove the majority of As removal, which is reasonable given that sulfide may reduc- 


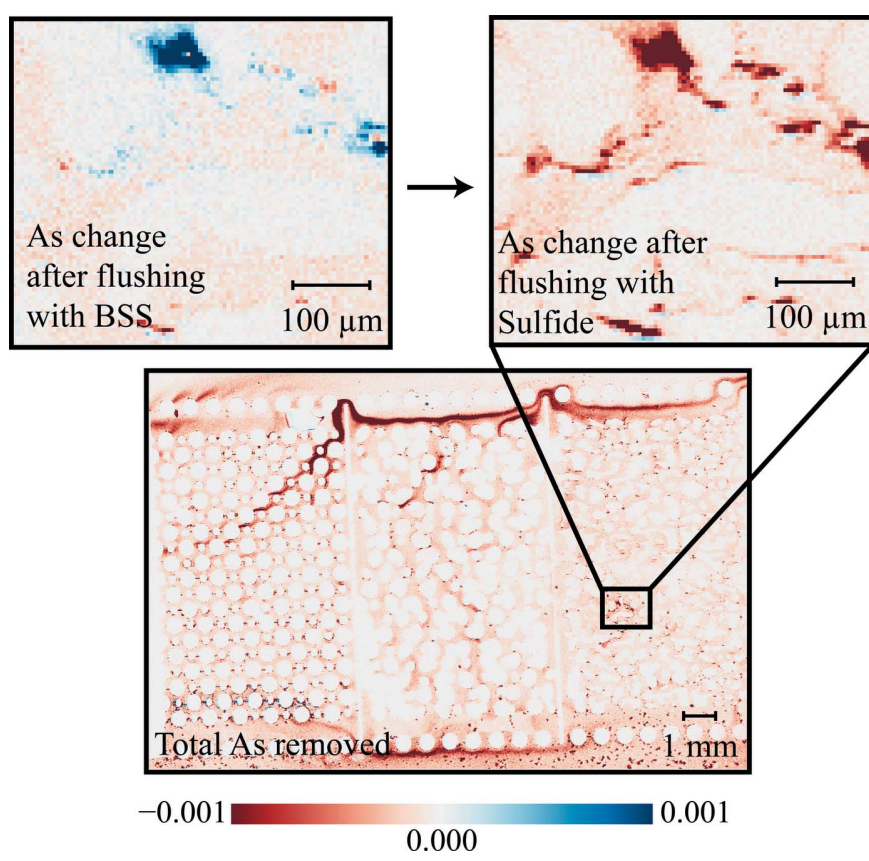

Figure 4

Difference maps of As between the various reaction stages for a parallelflow device. Negative values, in red, indicate a gain of As from the prior stage, while positive values, in blue, indicate a net loss of As.

tively dissolve the oxidized Fe solids, which would spur release of As into solution.

\subsection{XAS analysis}

XAS microprobe measurements around the $\mathrm{As}$ and $\mathrm{Fe}$ edges were taken in the different experiments to examine the speciation of As and $\mathrm{Fe}$ at different points in the parallel-flow devices. These scans were taken after the infused solutions were changed, once geochemical conditions appeared steady according to the collected fluorescence maps. Measured spectra are given in the supporting information (Figs. S3 and S4) alongside the locations they were taken (Fig. S5). When possible, multiple spectra were taken for averaging, though beam damage was observed during collection of As XANES spectra (see supporting information for details). Averaged spectra were fitted using a combination of standards which were measured previously (Kocar et al., 2006; Fendorf, 1999). In the case of $\mathrm{As}, \mathrm{As}^{\mathrm{V}}, \mathrm{As}^{\mathrm{III}}$ and $\mathrm{As}-\mathrm{S}$ are easily and readily discerned from XANES spectra and the three standards would cover the potential range of As species that would form.

A summary of the fitting results is given in Table 1. In contrast, however, a large range of Fe minerals and species exist, with less easily discerned spectra depending on the mineral formed (Root et al., 2013). For these fits, the representative minerals, lepidocrocite, green rust and pyrite, were used to broadly represent $\mathrm{Fe}^{\mathrm{III}}$ species, $\mathrm{Fe}^{\mathrm{II}}$ species and $\mathrm{Fe}-\mathrm{S}$ species, respectively (Mayhew et al., 2011). A summary of the best fit results is provided in Table 2. In devices where no sulfide has been injected, a mix of $\mathrm{As}^{\mathrm{III}}-\mathrm{As}^{\mathrm{V}}$ exists, similar to the mixture injected, and all $\mathrm{Fe}$ is observed to be $\mathrm{Fe}^{\mathrm{III}}$. For devices that have had sulfide injected, no As-S is observed in
Table 1

As XAS linear combination fitting results.

No As-S standard was used, as it was not observed in the samples. The referenced points indicate the location where XAS measurements were taken (Fig. S5). The experimental time these points were measured in is then given in the table. RMSE is the root-mean-squared error.

\begin{tabular}{lllll}
\hline Point & $\mathrm{As}^{\mathrm{III}}$ & $\mathrm{As}^{\mathrm{V}}$ & $\mathrm{RMSE}$ & $\mathrm{As}^{\mathrm{III}} / \mathrm{As}^{\mathrm{V}}$ ratio \\
\hline $\begin{array}{l}\text { During arsenic infusion } \\
1\end{array}$ & & & \\
2 & 0.44 & 0.56 & 0.03 & 0.77 \\
3 & 0.42 & 0.58 & 0.02 & 0.73 \\
4 & 0.41 & 0.59 & 0.02 & 0.69 \\
5 & 0.41 & 0.59 & 0.02 & 0.68 \\
6 & 0.48 & 0.52 & 0.02 & 0.93 \\
& 0.41 & 0.59 & 0.02 & 0.69 \\
During sulfide infusion & & & \\
1 & 0.27 & 0.73 & 0.03 & 0.37 \\
6 & 0.33 & 0.67 & 0.03 & 0.50 \\
8 & 0.37 & 0.63 & 0.03 & 0.60 \\
\hline
\end{tabular}

Table 2

Fe XAS linear combination fitting results.

Points were taken in another parallel-flow path device where the full experimental sequence had been run prior to XAS analysis. RMSE is the rootmean-squared error.

\begin{tabular}{lllll}
\hline Point & $\mathrm{Fe}^{\mathrm{III}}$ & $\mathrm{Fe}^{\mathrm{II}}$ & $\mathrm{Fe}-\mathrm{S}$ & RMSE \\
\hline 36 & 0.82 & 0.18 & 0 & 0.002 \\
38 & 0.73 & 0.23 & 0.03 & 0.004 \\
41 & 0.50 & 0.43 & 0.07 & 0.004 \\
\hline
\end{tabular}

the XANES spectra, but in the Fe XANES spectra, multiple locations have a coexistence of $\mathrm{Fe}^{\mathrm{III}}, \mathrm{Fe}^{\mathrm{II}}$ and in some places $\mathrm{Fe}-\mathrm{S}$. There is also a notable shift in the $\mathrm{As}^{\mathrm{III}} / \mathrm{As}^{\mathrm{V}}$ ratios at the collected XAS points from the time As was being injected to when sulfide was injected.

\subsection{Multiple-energy mapping}

Example results of multiple-energy (ME) mapping are shown in Fig. 4 for a parallel-flow device, with a set considering other regions of the same device given in the supporting information (Fig. S7). This technique in XRF mapping involves collecting multiple maps at different energies to glean spatial variations in oxidation state or mineralogy (Mayhew et al., 2011). The method relies on the shifts in fluorescence spectra that occur for different oxidation states, and in some cases coordinating ions, for a given element, relying on behavior typically observed when measuring XANES spectra. This is done by attributing the signals in maps taken at different X-ray energies to a few XAS standards for the species of interest. Here, fitted XAS results were used to inform the standards used for ME mapping. Since the fitted As XANES spectra only showed $\mathrm{As}^{\mathrm{III}}$ and $\mathrm{As}^{\mathrm{V}}$ in all of our devices, only those two standards were used to generate ME maps. While ME mapping using the selected Fe standards was attempted, the background signal in the glass interfered with fitting and obfuscated the spatial patterns of $\mathrm{Fe}$ in the pore spaces itself, showing Fe in spaces containing posts that should 
not have any Fe. This persisted even when the cover slip signal was subtracted.

The results of ME mapping for As in a parallel-flow device show that initially, after As infusion, there is a mix of $\mathrm{As}^{\mathrm{III}}$ and $\mathrm{As}^{\mathrm{V}}$, similar to what was expected based on the infused solution. Flushing with BSS does not seem to have a significantly strong impact on the As speciation in the mapped spaces, but after $\mathrm{S}$ infusion divergent behavior is observed. In one area, $\mathrm{As}^{\mathrm{III}}$ becomes the predominant As species (Fig. 3), but in another, the shift is clearly in the opposite direction towards $\mathrm{As}^{\mathrm{V}}$ (Fig. S7). It is not readily apparent what drives this divergent behavior, particularly because of the mixing of the pore regions as shown by the $\mathrm{Br}$ tracer.

\section{Discussion}

\subsection{Characteristics of flow in microfluidic devices}

Advective transport plays a central role in the transport of As, thus $\mathrm{Br}$ was used as a flow tracer. In devices that featured a pore structure that resulted in diverging flow, XRF mapping of $\mathrm{Br}$ distributions (Fig. 4) illustrates that a tighter central pore space results in a splitting of the flow, and accordingly $\mathrm{Br}$ is found predominantly on the side it was injected. This type of feature was previously used in benchmark experiments to study porous media flow in microfluidic devices (Oostrom $e t$ al., 2016). In that work, tighter pore spaces were used to create a converging flow path, while here we have demonstrated the efficacy of a pore space that creates divergent flow. In devices featuring parallel flow paths, the results of $\mathrm{Br}$ tracer studies clearly show that all pore regions are well mixed when fluorescence maps are taken, given that $\mathrm{Br}$ penetrates all pore spaces at a relatively even concentration (Fig. S2). The differences in these two devices' flow patterns clearly highlight a range of possibilities for the types of soil-relevant flow regimes that can be studied in microfluidic devices. For example, one could develop a series of devices featuring 'dead-end' channels, which could then be used to study diffusive processes, such as those which would mimic small fractures in pores which can be repositories for metal contaminants or soil carbon (McKinley et al., 2006). Alternatively, the pore spaces used here could be integrated into microfluidic chip systems that feature more advanced flow controls. A pressure-based flow switch was recently used to control the flow of nutrient to microbes that form biofilms and could also be integrated into the soil-like structure used here to examine time-variant solution conditions (Yawata et al., 2016).

There is also the possibility in these devices that the formation of the Fe precipitate could block flow. Indeed, this was leveraged in previous microfluidic studies to effectively create a $\mathrm{Fe}$ precipitate wall in the micromodel that might mimic a typical redox transition zone (Pearce et al., 2012). In that work, XRF mapping at the Fe $K$ edge of a sectioned device clearly demonstrated that the precipitated $\mathrm{Fe}$ had completely blocked the flow path. In the work here, $\mathrm{Fe}$ precipitates were formed using a similar process, but no evidence of significant pore blockage was observed. Br maps, all of which were taken after $\mathrm{Fe}$ precipitation had been completed, clearly show that minimal blockage of pore spaces with $\mathrm{Fe}$ precipitates is observed, owing to the presence of $\mathrm{Br}$ in the pore spaces. The reason for the difference most likely lies in the conditions for Fe injection and subsequent distribution: in the referenced work, a $15 \mathrm{~m} M \mathrm{Fe}^{\mathrm{II}}$ solution was used, but the injection rate is given as roughly $180 \mu \mathrm{h} \mathrm{h}^{-1}$ and the mixing of the $\mathrm{Fe}^{\mathrm{II}}$ and oxic solutions clearly creates a single line down the middle of the device (Pearce et al., 2012). The experiments here, however, used a $10 \mathrm{mM} \mathrm{Fe}^{\mathrm{II}}$ solution and an injection rate of only $100 \mu \mathrm{h}^{-1}$, which would result in a markedly slower delivery of $\mathrm{Fe}$. The comparatively lower amount of available $\mathrm{Fe}$ in the devices may result in less overall precipitate forming, leaving pore spaces unblocked. Additionally, the results of the $\mathrm{Br}$ tracer studies also show that flow mixing in either device configuration used here does not conform to a single-line mixing zone, thus the areas where $\mathrm{Fe}$ meets oxygenated BSS are broader than in the referenced work. This would create a wider distribution of Fe that would not block flow as the solid would not be concentrated in a single area.

\subsection{As and Fe trends in microfluidic devices}

In both devices used here, As conforms to the broad flow patterns previously discussed; in a diverging-flow device, As remains on the side it is injected, while in the parallel-flow device, As is found to be co-located with $\mathrm{Fe}$ in all spaces (Figs. 2 and 3). It is well established that both $\mathrm{As}^{\mathrm{III}}$ and $\mathrm{As}^{\mathrm{V}}$ will sorb extensively to $\mathrm{Fe}$ (hydr)oxide minerals, so it is reasonable to observe this pattern of co-location with $\mathrm{Fe}$ as opposed to matching the spread of $\mathrm{Br}$ (Wolthers et al., 2005; Farquhar et al., 2002; Dixit \& Hering, 2003). Further evidence that the As is sorbed to $\mathrm{Fe}$ (hydr)oxides appears upon comparison of XRF maps taken during As injection against those taken during flushing of a parallel-flow device with BSS (Fig. 4). While the maps indicate some amount of As redistribution, summations of loss and gain in the mapped areas do not indicate a net loss of As during flushing with the BSS. Since the original As-containing solution was made up in the BSS mixture, it is reasonable that flushing with BSS would not spur significant changes in As retention. This further reinforces the conclusion that As is sorbing to the precipitated Fe (hydr)oxide solids.

Other works studying As sorption to iron (hydr)oxides demonstrated that $\mathrm{As}^{\mathrm{V}}$ and $\mathrm{As} \mathrm{s}^{\mathrm{III}}$ sorb differentially to various Fe (hydr)oxide minerals, with As ${ }^{\text {III }}$ sorbing more extensively than $\mathrm{As}^{\mathrm{v}}$ to both ferrihydrite and goethite at circumneutral pH (Dixit \& Hering, 2003; Jönsson \& Sherman, 2008; Kocar et al., 2006). ME mapping results show a roughly equivalent distribution of $\mathrm{As}^{\mathrm{III}}$ and $\mathrm{As}^{\mathrm{V}}$ after arsenic injection and during flushing with the BSS (Fig. 3 and Figs. S7 and S8 for Fe distributions in same area). However, the As XAS points taken suggest that there is marked variation in the distribution of the two species after injection, with generally less $\mathrm{As}^{\mathrm{III}}$ versus $\mathrm{As}^{\mathrm{V}}$, the opposite of previously reported trends predicted by sorption. The presence of flow in these systems 
immediately makes it difficult to draw direct comparisons between the results here and previous studies of As, particularly since many studies of As sorption have been conducted using batch reactors and did not consider competitive sorption between the two As species. Careful design of a device flow path may allow the creation of a device that can clearly demonstrate differential sorption of the two As species, but this work shows that the two species do not demonstrate differential transport at the scales considered here $(\sim 1 \mathrm{~cm})$.

Injection of sulfide into the parallel-flow device resulted in the net release of As, as clearly indicated in the change of As indicated in Fig. 4. The low concentrations of both As and sulfide used preclude the formation of As-S solid precipitates. This is confirmed by the XAS results, which did not show measurable As-S species (Kocar et al., 2006; Wolthers et al., 2005). The XAS results and ME mapping indicate that in some areas $\mathrm{As}^{\mathrm{III}}$ has increased, while in others an increase in the ratio of $\mathrm{As}^{\mathrm{V}}$ to $\mathrm{As}^{\mathrm{III}}$ is observed. It is not immediately clear, however, why As oxidation would be occurring, rather than As reduction. The conditions of Fe (hydr)oxide precipitation are similar to those of previous studies, where these conditions produced a poorly crystalline $\mathrm{Fe}^{\mathrm{III}}$ (hydr)oxide mineral with minimal reduced $\mathrm{Fe}$ and no $\mathrm{Fe}-\mathrm{S}$ species (Schwertmann \& Cornell, 2000; Pearce et al., 2012). However, Fe XAS linear combination fitting (LCF) of Fe solids after sulfide infusion shows the presence of reduced $\mathrm{Fe}$ species, as well as the potential formation of $\mathrm{Fe}-\mathrm{S}$ phases (Table 2). It is most likely, therefore, that the sulfide resulted in reduction of Fe solids. Iron solids containing $\mathrm{Fe}^{\mathrm{II}}$ typically have less extensive sorption of As than $\mathrm{Fe}^{\mathrm{III}}$ hydroxides, which would help explain why there is a release of As when certain amounts of sulfide are injected (Farquhar et al., 2002). Comparison of Fe maps also shows that there is minimal change in the total $\mathrm{Fe}$ present (Figs. S2 and S8), suggesting that the reductions observed resulted in transformation of the Fe solids present, rather than reductive release of $\mathrm{Fe}^{\mathrm{II}}$. Sorption studies of As with reduced $\mathrm{Fe}$ minerals can explain why the amount of $\mathrm{As}^{\mathrm{V}}$ also increases, as reduced $\mathrm{Fe}$ minerals, particularly mackinawite, have been observed to retain $\mathrm{As}^{\mathrm{V}}$ more strongly than $\mathrm{As}^{\mathrm{III}}$ (Wolthers et al., 2005). Thus, injection of sulfide resulted in a release of As, which is directly tied to the reduction of Fe solids.

\subsection{Implications for future studies of microscale processes}

The micromodels developed here have clearly met the promise of combining microfluidic device studies with a detailed spatial analysis of geochemical trends using XRF microprobe spectroscopy. The work done here illustrates that the full range of microprobe techniques can be brought to bear on these devices for incident X-ray energies as low as $7 \mathrm{keV}$, including the collection of XAS point scans, XRF mapping and ME mapping. This development was primarily enabled by the thin glass window material, although some limitations still exist even with these devices. Background spectra of the glass show a number of interfering elements, notably $\mathrm{Fe}$ and $\mathrm{Ba}$, which will produce fluorescence even when not present in the microfluidic channel. Here, the Fe inter- ference prevented ME mapping, but XAS spectra and general XRF mapping were not affected. A notable innovation in the attachment method of the thin glass is that it is not material specific. Previous microfluidic device studies using $500 \mu \mathrm{m}$ thick glass slides sealed their devices by anodically bonding the glass to a silicon wafer, but this requires glass with a high ion content and specialized equipment that is necessary for the bonding to occur (Cui, 2008). It should be relatively simple to select the window material that is the most amenable to the geochemical system being studied and attach it to a device using the transfer adhesion technique used here. The use of a thin polycarbonate film, for example, could enable studies without the presence of the interferences above and could be used at lower energies, potentially as low as $4 \mathrm{keV}$, depending on the thickness of the material.

In this study, silicon devices with a thin layer of thermal silicon oxide were selected owing to their geochemical similarity to natural earth materials (e.g. quartz), but alternate device materials could readily be used, depending on the needs of a given experiment. It is very common, for example, to use PDMS cast into a master mold, typically etched photoresist, for microfluidic devices using oxygen-respiring bacteria, as the PDMS allows for oxygen diffusion (Friend \& Yeo, 2010; Lee et al., 2000). These are also often preferred owing to the significantly less expensive and simpler fabrication process compared with etched silicon micromodels. A common method of sealing these devices is by plasma-bonding the PDMS to a glass surface, which should easily extend to the thin glass used here. Alternatively, it would be possible to etch a quartz wafer and seal it with the thin glass to create completely transparent devices.

Another possible innovation would be the development of 3D structures that would more readily mimic the natural structures found in porous media. Some work has already been performed in this regard, where devices featuring multiple etch depths have been fabricated to study multiphase flow in porous media (Xu et al., 2017). Similar techniques can also be used to fabricate a wider range of feature sizes, thereby capturing the large variations in pore sizes that can be found in natural settings (Zachara et al., 2013). The flexibility of general microfluidic device designs, in combination with the flexible sealing method used here, can provide a broad range of potential devices that could be developed for analysis using XRF microprobe techniques.

It is well established for many soil systems that processes acting at pore scales can drive geochemical trends at larger scales. The use of the thin glass window micromodels developed here would provide an ideal system with which to study these processes. One subject that would be particularly well suited for study would be the naturally reducing zones (NRZs) that have been highlighted as controlling the long-term persistence of $\mathrm{U}$ at the Rifle, Colorado, USA, site (Zachara et al., 2013). One could design a device that could be loaded with organic carbon in such a way that it creates the boundary mimicking such a zone and then be used to study the release and retention of $U$ as that zone is oxygenated and then deoxygenated. 
Lastly, while the work here has been primarily focused on the use of these devices for investigating biogeochemical processes in soil, these devices could prove useful for the study of a variety of other microscale processes, where mapping and characterization of elemental chemistry in a flow field are of interest.

\section{Related literature}

The following references, not cited in the main body of the paper, have been cited in the supporting information: Mogren et al. (2013); Smith et al. (2005).

\section{Acknowledgements}

This work was supported by the MIT Department of Civil and Environmental Engineering, Center for Environmental Health Sciences, Microsystems Technology Laboratory and staff at the DOE NSLS-II. In particular, the guidance provided by Kurt Broderick on microfabrication and the assistance in XRF data collection and analysis provided by Ryan Tappero and Alvin Acerbo at NSLS-II made this work possible. Preliminary XRF analysis on a microfluidic prototype was performed at the Stanford Synchrotron Radiation Lightsource beamline 2-3, with guidance provided by Sam Webb. The authors declare no conflict of interest.

\section{Funding information}

The following funding is acknowledged: Massachusetts Institute of Technology. This work was performed in part at the Harvard University Center for Nanoscale Systems (CNS), a member of the National Nanotechnology Coordinated Infrastructure Network (NNCI), which is supported by the National Science Foundation under NSF ECCS award No. 1541959 .

\section{References}

Berg, M., Tran, H. C., Nguyen, T. C., Pham, H. V., Schertenleib, R. \& Giger, W. (2001). Environ. Sci. Technol. 35, 2621-2626.

Boek, E. S. \& Venturoli, M. (2010). Comput. Math. Appl. 59, 23052314.

Burton, E. D., Johnston, S. G. \& Kocar, B. D. (2014). Environ. Sci. Technol. 48, 13660-13667.

Chomsurin, C. \& Werth, C. J. (2003). Water Resour. Res. 39, 1265.

Cui, Z. (2008). Encyclopedia of Microfluidics and Nanofluidics, edited by D. Li, pp. 50-54. Boston, Massachusetts, USA: Springer US.

Dixit, S. \& Hering, J. G. (2003). Environ. Sci. Technol. 37, 4182-4189.

Edelstein, A., Amodaj, N., Hoover, K., Vale, R. \& Stuurman, N. (2010). Curr. Protoc. Mol. Biol. 92, 14.20.1-14.20.17.

Edelstein, A. D., Tsuchida, M. A., Amodaj, N., Pinkard, H., Vale, R. D. \& Stuurman, N. (2014). J. Biol. Methods, 1, e10.

Fanizza, M. F., Yoon, H., Zhang, C., Oostrom, M., Wietsma, T. W., Hess, N. J., Bowden, M. E., Strathmann, T. J., Finneran, K. T. \& Werth, C. J. (2013). Water Resour. Res. 49, 874-890.

Farquhar, M. L., Charnock, J. M., Livens, F. R. \& Vaughan, D. J. (2002). Environ. Sci. Technol. 36, 1757-1762.

Fendorf, S. (1999). Synchrotron X-ray Methods in Clay Science. CMS Workshop Lectures, Vol. 9, edited by D. G. Schulze, J. W. Stucki \&
P. M. Bertsch, pp. 19-67. Boulder, Colorado, USA: The Clay Minerals Society.

Foster, A. L. \& Kim, C. S. (2014). Rev. Mineral. Geochem. 79, 257369.

Friend, J. \& Yeo, L. (2010). Biomicrofluidics, 4, 026502.

Huhmann, B. L., Harvey, C. F., Uddin, A., Choudhury, I., Ahmed, K. M., Duxbury, J. M., Bostick, B. C. \& van Geen, A. (2017). Environ. Sci. Technol. 51, 11553-11560.

Jaho, S., Athanasakou, G. D., Sygouni, V., Lioliou, M. G., Koutsoukos, P. G. \& Paraskeva, C. A. (2016). Cryst. Growth Des. 16, 359370.

Janot, N., Lezama Pacheco, J. S., Pham, D. Q., O'Brien, T. M., Hausladen, D., Noël, V., Lallier, F., Maher, K., Fendorf, S., Williams, K. H., Long, P. E. \& Bargar, J. R. (2016). Environ. Sci. Technol. 50, 46-53.

Johnson, J. E., Webb, S. M., Thomas, K., Ono, S., Kirschvink, J. L. \& Fischer, W. W. (2013). Proc. Natl Acad. Sci. USA, 110, 1123811243.

Jönsson, J. \& Sherman, D. M. (2008). Chem. Geol. 255, 173-181.

Kim, D.-S. \& Fogler, H. S. (2000). Biotechnol. Bioeng. 69, 47-56.

Kim, S. H., Cui, Y., Lee, M. J., Nam, S.-W., Oh, D., Kang, S. H., Kim, Y. S. \& Park, S. (2011). Lab Chip, 11, 348-353.

Kocar, B. D., Herbel, M. J., Tufano, K. J. \& Fendorf, S. (2006). Environ. Sci. Technol. 40, 6715-6721.

Lee, S. G., Lee, H., Gupta, A., Chang, S. \& Doyle, P. S. (2016). Adv. Funct. Mater. 26, 4896-4905.

Lee, T. M. H., Lee, D. H. Y., Liaw, C. Y. N., Lao, A. I. K. \& Hsing, I.-M. (2000). Sens. Actuators A Phys. 86, 103-107.

Marty, F., Rousseau, L., Saadany, B., Mercier, B., Français, O., Mita, Y. \& Bourouina, T. (2005). Microelectron. J. 36, 673-677.

Masue-Slowey, Y., Kocar, B. D., Bea Jofré, S. A., Mayer, K. U. \& Fendorf, S. (2011). Environ. Sci. Technol. 45, 582-588.

Mayhew, L. E., Webb, S. M. \& Templeton, A. S. (2011). Environ. Sci. Technol. 45, 4468-4474.

McKinley, J. P., Zachara, J. M., Liu, C., Heald, S. C., Prenitzer, B. I. \& Kempshall, B. W. (2006). Geochim. Cosmochim. Acta, 70, 18731887.

Michelson, K., Sanford, R. A., Valocchi, A. J. \& Werth, C. J. (2017). Environ. Sci. Technol. 51, 11660-11668.

Mogren, C. L., Webb, S. M., Walton, W. E. \& Trumble, J. T. (2013). Environ. Pollut. 180, 78-83.

Neumann, R. B., Ashfaque, K. N., Badruzzaman, A. B. M., Ashraf Ali, M., Shoemaker, J. K. \& Harvey, C. F. (2010). Nat. Geosci. 3, 4652.

Nicholas, S. L., Erickson, M. L., Woodruff, L. G., Knaeble, A. R., Marcus, M. A., Lynch, J. K. \& Toner, B. M. (2017). Geochim. Cosmochim. Acta, 211, 228-255.

Oostrom, M., Mehmani, Y., Romero-Gomez, P., Tang, Y., Liu, H., Yoon, H., Kang, Q., Joekar-Niasar, V., Balhoff, M. T., Dewers, T., Tartakovsky, G. D., Leist, E. A., Hess, N. J., Perkins, W. A., Rakowski, C. L., Richmond, M. C., Serkowski, J. A., Werth, C. J., Valocchi, A. J., Wietsma, T. W. \& Zhang, C. (2016). Comput. Geosci. 20, 857-879.

Pearce, C. I., Wilkins, M. J., Zhang, C., Heald, S. M., Fredrickson, J. K. \& Zachara, J. M. (2012). Environ. Sci. Technol. 46, 7992-8000.

Prietzel, J., Thieme, J., Eusterhues, K. \& Eichert, D. (2007). Eur. J. Soil Sci. 58, 1027-1041.

Python Software Foundation (2010). Python Language Reference, https://docs.python.org/3/reference/.

Ravel, B. \& Newville, M. (2005). J. Synchrotron Rad. 12, 537-541.

Root, R. A., Fathordoobadi, S., Alday, F., Ela, W. \& Chorover, J. (2013). Environ. Sci. Technol. 47, 12992-13000.

Schwertmann, U. \& Cornell, R. M. (2000). Iron Oxides in the Laboratory, 2nd ed. Weinheim: Wiley-VCH Verlag GmbH.

Smith, P. G., Koch, I., Gordon, R. A., Mandoli, D. F., Chapman, B. D. \& Reimer, K. J. (2005). Environ. Sci. Technol. 39, 248-254.

Song, W., de Haas, T. W., Fadaei, H. \& Sinton, D. (2014). Lab Chip, 14, 4382-4390. 
Swanner, E. D., Webb, S. M. \& Kappler, A. (2019). Am. Mineral. 104, 917-928.

Virtanen, P., Gommers, R., Oliphant, T. E., Haberland, M., Reddy, T., Cournapeau, D., Burovski, E., Peterson, P., Weckesser, W., Bright, J., van der Walt, S. J., Brett, M., Wilson, J., Millman, K. J., Mayorov, N., Nelson, A. R. J., Jones, E., Kern, R., Larson, E., Carey, C. J., Polat, İ., Feng, Y., Moore, E. W., VanderPlas, J., Laxalde, D., Perktold, J., Cimrman, R., Henriksen, I., Quintero, E. A., Harris, C. R., Archibald, A. M., Ribeiro, A. H., Pedregosa, F., van Mulbregt, P. \& SciPy 1.0 Contributors (2020). Nat. Methods, 17, 261-272.

Wang, Y., Wei, N., Zhang, C., Wietsma, T. W., Bonneville, A., Li, X., Li, M. \& Wang, Z. (2018). Microfluid. Nanofluid. 22, 101.

Webb, S. M., McNulty, I., Eyberger, C. \& Lai, B. (2011). AIP Conf. Proc. 1365, 196-199.
Wolthers, M., Charlet, L., van Der Weijden, C. H., van der Linde, P. R. \& Rickard, D. (2005). Geochim. Cosmochim. Acta, 69, 34833492.

Xu, K., Liang, T., Zhu, P., Qi, P., Lu, J., Huh, C. \& Balhoff, M. (2017). Lab Chip, 17, 640-646.

Yawata, Y., Nguyen, J., Stocker, R. \& Rusconi, R. (2016). J. Bacteriol. 198, 2589-2595.

Yoon, H., Valocchi, A. J., Werth, C. J. \& Dewers, T. (2012). Water Resour. Res. 48, 1-12.

Zachara, J. M., Long, P. E., Bargar, J., Davis, J. A., Fox, P., Fredrickson, J. K., Freshley, M. D., Konopka, A. E., Liu, C., McKinley, J. P., Rockhold, M. L., Williams, K. H. \& Yabusaki, S. B. (2013). J. Contam. Hydrol. 147, 45-72.

Zhang, C., Liu, C. \& Shi, Z. (2013). Environ. Sci. Technol. 47, 41314139. 